\title{
Local Instruction Theories at the University Level: An Example in a Linear Algebra Course
}

\author{
Andrea Cárcamo ${ }^{{ }^{*}}$, Claudio Fuentealba ${ }^{1}$, Diego Garzón ${ }^{2}$ \\ ${ }^{1}$ Facultad de Ciencias de la Ingeniería, Universidad Austral de Chile, CHILE \\ ${ }^{2}$ Instituto de Educación y Pedagogía, Universidad del Valle, COLOMBIA
}

Received 10 April 2019 • Accepted 19 April 2019

\begin{abstract}
In order to promote the design of innovative instructional activities at the Linear Algebra, we perform a design-based research project to explore how to teach Linear Algebra at the university level. In this article, we present the results of three cycles of a teaching experiment that we carried out to design, try out, and improve a local instruction theory (LIT) on the teaching of the concepts of spanning set and span in Linear Algebra with first-year engineering students. In a retrospective analysis, we looked for patterns in the data set of all the experiments, and we identified key learning moment of the students. Based on these patterns, we formulated a LIT to support the construction of the concepts of spanning set and span.
\end{abstract}

Keywords: emergent models, instructional design, linear algebra, local instruction theory

\section{INTRODUCTION}

To support teachers in the development of innovation-oriented instructional sequences, the development of local instructional theories is necessary (Nickerson \& Whitacre, 2010). A local instruction theory (LIT) informs teachers about how innovative educational approaches work so that they can adapt them to their classrooms (Gravemeijer \& van Eerde, 2009).

Dorier and Sierpinska (2001) suggest that Linear Algebra teachers require suggestions about the structure of the knowledge they teach, in conjunction with a supply of good examples, questions, exercises, and problems. These teachers assess the documents that provide this, among which are the local instruction theories (LITs). For this reason, it is important to design these types of theories in this course. Larsen (2013) notes that a LIT describes how a specific subject of mathematics could be taught based on specific design principles.

In this same sense, Gravemeijer (2004a) specifies that a LIT informs the teachers about the goals for learning, the instructional activities, and the tools (physical objects, symbols, or notation) that will be used and a hypothetical learning process conjectured in which anticipates how students' thinking and understanding could evolve when instructional activities are used in the classroom.

The intention of developing a LIT is for it to be able to function as a frame of reference for teachers who wish to adapt the sequence of the instruction corresponding to their classrooms and personal objectives (Gravemeijer \& Cobb, 2013). In this way, Gravemeijer (2004b) states that the LITs offer frames of reference that allow for the design of hypothetical learning trajectories (HLTs). Specifically, the idea is for teachers to use LIT to choose instructional activities and design HLTs for their students (Gravemeijer, 2004a).

In the research literature, there are few examples of LITs (Nickerson \& Whitacre, 2010). At the university level, a LIT has been built on the basic principles of the rate of change and speed (Doorman \& Gravemeijer, 2009) and the group and isomorphism (Larsen, 2013). This reveals the need to contribute to the construction of LITs at the university level. For this, we have chosen the Linear Algebra course, because we want to help with its teaching and learning since it is a cognitively and conceptually difficult subject (Dorier \& Siernpiska, 2001).

(C) 2019 by the authors; licensee Modestum Ltd., UK. This article is an open access article distributed under the terms and conditions of the Creative Commons Attribution License (http://creativecommons.org/licenses/by/4.0/). \andrea.carcamo@uach.cl (*Correspondence) $\bigotimes$ cfuentealba@uach.cl 


\section{Contribution of this paper to the literature}

- This research describes the development of a local instruction theory (LIT) at the university level, where there are few examples.

- $\quad$ The LIT presented in this study is intended as a reference for teachers, researchers, and designers who wish to innovate Linear Algebra courses, as well as in other mathematics courses at the university level.

- The actions of the teachers are incorporated into the LIT components mentioned by Gravemeijer (2004a)

- $\quad$ The LIT presented in this article is the first LIT based on emergent models and mathematical modeling for the concepts of spanning set and span.

The concepts of spanning set and span were chosen to propose a LIT for Linear Algebra. These are essential because of their relationship with other topics in this course as the basis and dimension of a vector space (Stewart \& Thomas, 2010). However, nature and type are thinking necessary to understand Linear Algebra (Dorier \& Sierpinska, 2001) lead to students having difficulty learning these concepts. Carlson (1997) notes that students feel confused and disoriented when they begin the study of this type of content. Specifically, Nardi (1997) warns that students confuse the terms of spanning set and span, using them interchangeably.

To support the construction of the spanning set and span, instructional activities are designed, which are a crucial ingredient of the LIT (Gravemeijer, 1998), considering the emergent models heuristic. Emergent models allow students to progress from informal mathematical activity to more sophisticated reasoning. This transition from informal mathematical activity to formal mathematical reasoning is associated with a change in the students' thinking, which goes from thinking of the situation that is experientially real to him to a focus on mathematical relationships (Gravemeijer, 1999).

A real-world situation has been chosen, which is the development of secure passwords used to evoke the problem of contextual knowledge and informal strategies (Gravemeijer, 1998). To solve this problem, mathematical modeling is used as a tool to help the study of mathematics (Julie \& Mudaly, 2007). Also, the mathematical modeling cycle proposed by Blum and Leiss (2007) is considered for guiding students in solving the problem of developing strong passwords.

The objective of this article is to propose a LIT for the concepts of spanning set and span on the basis of the results of three cycles of a teaching experiment. In particular, a LIT based on the emergent models heuristic and mathematical modeling to promote curricular innovation in Linear Algebra. This is because we agree with Lewis and Blunk (2012) that strong curricular support for teachers can result in a higher quality of mathematical instruction.

\section{THEORETICAL PERSPECTIVE}

\section{Emergent Models Heuristic}

Emergent models are one of the main heuristics aimed at instructional design, and which can help designers/researchers to develop LITs. This heuristic is part of the theory of instruction known as Realistic Mathematical Education (RME), and it stands out because it helps students to build a mathematical reality by themselves that does not exist for them (Gravemeijer, 2007). This is done through a process of gradual growth where formal mathematics comes to the fore as a natural extension of their experience (Gravemeijer, 1999). In this way, emergent models are presented as an alternative to instructional approaches that focus on the teaching of ready-made representations (Gravemeijer, 2002); that is, they only transmit knowledge in a decontextualized way.

The emergent models focus on the role they play in the individual learning of the students and the collective mathematical development of the community of the class. Each emergent model refers to the notion of a model that can come to the fore as a model of informal mathematical activity and can eventually become a model for more formal mathematical reasoning (Gravemeijer, 2004b). The term model is considered as a vehicle to promote and support progressive mathematization (Gravemeijer, 1994). The model can refer to a work environment or a verbal description, as well as the forms of symbolization and notation. As a consequence, the symbolizations that are embedded in the modeling process and that constitute the model can change over time (Gravemeijer, Cobb, Bowers, \& Whitenack, 2000).

The change from a model-of to a model-for coincide with a change in students' thinking, from thinking about the modeled situation to thinking about a focus on mathematical relationships. In this way, students gradually build a framework of mathematical relationships. The model begins to derive its meaning from this new framework of mathematical relationships and becomes more critical as a basis for more formal mathematical reasoning (Gravemeijer, 2002). In this sense, the model is first presented as a model of informal strategies that provide a frame 
of reference for students. Over time the model gradually takes on a life of its own. The model becomes an entity in itself and begins to serve as a model for more formal reasoning (Gravemeijer \& Stephan, 2011).

For the transition from a model-of to a model-for, Gravemeijer (1999) details four levels of activity that do not involve any strictly ordered hierarchy, known as situational, referential, general, and formal. The situational activity involves students working toward the mathematical objectives through an experience that is real to them. The referential activity involves models of descriptions, concepts, and procedures that relate to the problem of situational activity. The general activity involves models to explore, to reflect upon, and to generalize about what appeared at the previous level, but with a mathematical focus on strategies, without making any reference to the initial problem. The formal activity leads students to reflect the emergence of a new reality in mathematics; therefore, it involves working with procedures and conventional notations.

The emergent models heuristic does not indicate to instructional designers where to find appropriate models, but it does describe what an emergent model may seem like, what its characteristics are and how it works. In this way, the heuristic can help designers in their choice of models (Gravemeijer \& Stephan, 2011).

\section{Mathematical Modeling}

Lesh and Caylor (2007) emphasize that statements of curricular norms, oriented toward the future, identify modeling as a subject that should receive attention. This is especially true in institutions that intend to prepare students for future professions and productive participation in dynamic societies. It is essential for citizens to be informed on the primary use of concepts to be able to model data and make sense of the graphics, diagrams, tables and other types of mathematical tools that are frequent in the media.

We agree with Niss (2012) that the introduction of mathematical modeling in the classroom is necessary since there is no guaranteed transfer of knowledge and mathematical skills to knowledge and skills related to models and modeling.

By introducing mathematical modeling in the classroom, it is expected that when students are confronted with problematic situations of interest, they will be able to explore ways to represent them in mathematical terms, explore the relationships that appear in those representations, manipulate and develop powerful ideas that can be channeled towards the mathematics that is desired to be taught (Lesh \& English, 2005).

In this study, an educational perspective of mathematical modeling is adopted (Kaiser \& Schwarz, 2010). Mathematical modeling is a vehicle or a tool to help the study of mathematics that motivates students and provides a basis for the development of mathematical content (Julie \& Mudaly, 2007). Also, to guide the students in the resolution of the modeling task proposed in this study, the modeling cycle proposed by Blum and Leiss (2007) is used.

\section{METHODOLOGY}

Design-based research (DBR) is the systematic study of the design, development, and evaluation of educational interventions such as programs, strategies and teaching-learning materials, products, and systems. Likewise, it is interested in finding solutions to complex problems in educational practice. This is done to advance the knowledge of the characteristics of these interventions, the processes of their design (or execution) or the validation of theories (Plomp, 2013).

Regarding the DBR, Grameveijer (2004a) points out that "the core of this type of research is formed by classroom teaching experiments that center on the development of instructional sequences and the local instructional theories that underpin them" (p. 108). Also, he points out that the purpose of this type of research is to provide an empirically grounded theory on how researchers think that a specific set of instructional activities could work.

In the DBR, Cobb and Gravemeijer (2008) specify that three phases are distinguished: (1) the preparation of the experiment; (2) the teaching of the experiment (experimentation to promote learning); and, (3) the retrospective analysis. In the second phase, interventions are carried out in the classroom, along with later iterations of threestep cycles: design (design and formulation of hypotheses), testing (intervention in the classroom together with data collection) and reviewing (analysis of the data) with the purpose of reviewing and reformulating the hypothesis.

\section{Phase 1: Preparation of the Experiment}

The first phase included the elaboration of an HLT for the span and spanning set concepts of Linear Algebra, which implied that the elements of the HLT mentioned by Simon (1995) were specified: (a) the goal of the learning; (b) the hypothetical learning process; and, (c) the learning tasks. 
Table 1. Summary of the HLT applied in cycle 1 of the teaching experiment Hypothetical learning process

(a) The students, using their current knowledge of linear combination and its relation to vectors, construct an $\mathrm{R}^{\mathrm{n}}$ vector with generic scalars. (b) From this construction, they obtain at least one example of a vector that arises from the application of the $\mathrm{R}^{\mathrm{n}}$ vector.

(1) Students coordinating their knowledge about sets and its notation, they describe two sets, $A$ and $G$, from the vector of $R^{n}$ with generic scalars that they constructed in task 1. (2) They describe analytically by extension the set $A$. This new set has the vectors that, when combined linearly with scalars, they obtain the vector constructed in task 1. (3) They describe by understanding the set $G$ which has all the vectors that are generated when it is assigned values to the scalars of the vector constructed in task 1. (4) From the individual analysis of both sets, $A$ and $G$, and from the relationships that students establish between these sets, they characterize the concepts of spanning set and span in terms of its cardinality, its mathematical notation and the inclusion of one over another. (5) They link the set $A$ with the concept of spanning set, meanwhile the set $G$ it is related with the concept of span.

(a) Students coordinate the analytical notation associated with the spanning set and the span and recognize that the set $B$ has the notation of a span while the set $C$ corresponds to the notation of a recognize that the set $B$ has the notation of a span while the set $C$ corresponds to the notation of a $\quad C(B=\langle(1,0,0),(0,1,0),(0,0,2)>$,
spanning set. (b) Students coordinate the analytical notation and the cardinality of the spanning set and $C=\{(1,0,0),(0,2,0),(0,0,1)\}$ have the same the span. They recognize that sets $B$ and $C$ do not have the same number of elements, because the set $B$ number of elements.

represents a span (has infinite vectors), unlike of the set $C$ that represents a spanning set (contains only three vectors).

(a) Students coordinate the definition of spanning set and span, and they identify $C=\{(1,0),(0,-1)\}$ as a spanning set of a space of $R^{2}$. (b) Using the definition of the span, the students perform a linear Task $3 b$ : To establish whether it is true spanning set of a space of $R^{2}$. (b) Using the definition of the span, the students perform a linear or false that the vector $(2,-3)$ belongs to vector $(2,-3)$ to determine if these scalars exist. (c) Coordinating the span definition with the vector $(2,-$ $3)$, that can be written as a linear combination of the vectors of set $C$, the students determine that this vector belong to the span generated by $C$.

(a) Students coordinate the definition of the span and the representation of points in the Cartesian plane. They multiply by different scalars the vector of set A and represent in the Cartesian plane, the vectors obtained from those products. (c) Students observe the points represented in the Cartesian plane and using the graphical representation of a line, and they determine that the span generated by $A$ correspond to a line. (d) Students coordinate the notation of the equation of a line and using the definition of the span; they write in analytic form the span of $\mathrm{R}^{2}$ generated by the set $A=\{(2,0)\}$.

Task and its description

Task 1: To create a mathematical model that contains vectors and that allows for the creation of secure passwords.

Task 2: To make an analogy table

between their password generator and the concepts of spanning set and span.

Task

Task $3 c$ : To represent graphically and
analytically the span $\mathrm{R}^{2}$ generated by the set $A=\{(2,0)\}$.

Task 3a: Determine whether sets $B$ and

The learning goal was for students to understand the concepts of generator set and generated space with an ad hoc designed instructional sequence based on the heuristics of emergent models and mathematical modeling. The hypothetical learning process and the design of the tasks of the HLT of cycle 1 of the teaching experiment (see Table 1) was based on the theoretical framework of our study (emergent models and mathematical modeling); specific Linear Algebra textbooks (Lay, 2007; Grossman, 1996; Lipschutz, 1992); the difficulties students had with this course (Nardi, 1997, Carlson, 1997, 2004); and the results of research on teaching the learning of the concepts of spanning set and span (Ball et al., 1998, Kú, Trigueros \& Oktaç, 2008; Kú, 2012; Wawro, Rasmussen, Zandieh, Sweeney, \& Larson, 2012).

The emergent models guided the design and structure of the HLT. Meanwhile, mathematical modeling was used as a teaching tool. In the design of the tasks of the HLT, following Drijvers (2003), a fundamental question was: What significant problems can promote cognitive development in line with the objectives of the HLT? To answer this question, we sought a problem that initially led the students to models-of this concrete situation, but that had the potential to become models-for new mathematical relations.

For the preparation of the initial problem of our HLT, the characteristics of a modeling task according to Galbraith (2007) were taken into account; that is, consistency with a stated purpose and the introduction of realworld modeling tasks. In our case, the objective was for the students to build a spanning set and span in a realworld context. Likewise, the task that involved the use of the modeling cycle is from the real world and referred to the current environment of the participants of the teaching experiment. This was because it was inserted into the context of generating passwords, something that they must do on a daily basis to prevent their social networks or other web pages they enter from being entered into by strangers.

Regarding the role of the teacher, the HLT was designed so that the teacher would play a proactive role during each cycle of the teaching experiment. In other words, the teacher establishing the appropriate culture of the class; choosing and presenting learning tasks; organizing group work; selecting the possible topics for discussion, and orchestrating them (Gravemeijer, 2004a). Therefore, it was assumed that the teacher would support the students in their process of building the generator set and generated space. The central actions of the teacher while applying the HLT in cycle 1 of the teaching experiment are shown in Figure 1. 
Tasks of the HLT of cycle 1

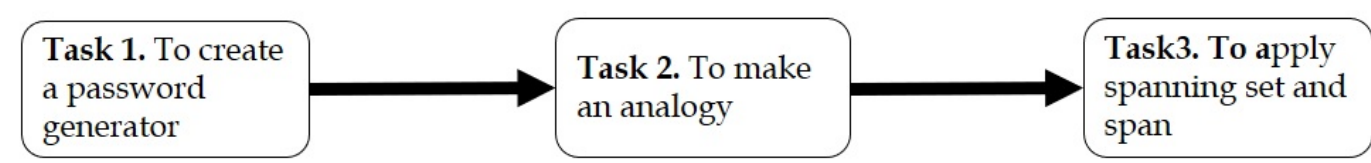

\section{Main actions of the teacher}

To define spanning
set and span. $\quad \begin{aligned} & \begin{array}{l}\text { Point out how to distinguish } \\ \text { between spanning set and } \\ \text { span. }\end{array} \\ & \text { spand }\end{aligned}$

Manage social interactions in class and guide students toward learning of spanning set and span

Figure 1. Main actions of the teacher while applying the HLT in cycle 1 of the teaching experiment.

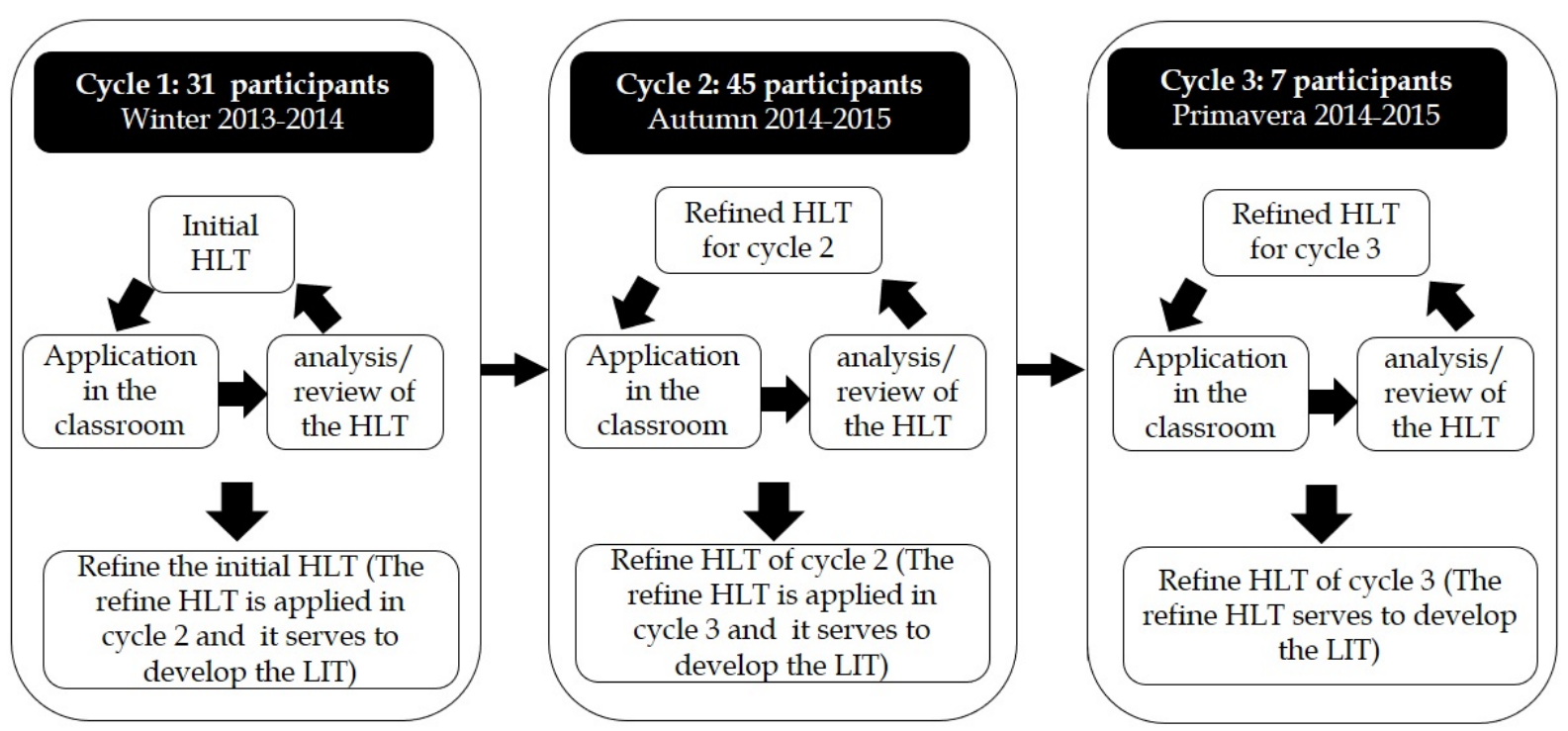

Figure 2. The three cycles of the teaching experiment carried out in our research.

\section{Phase 2: Teaching Experiment}

The HLT is (re) designed, tested and reviewed in the phase of the teaching experiment. While some conjectures are generated and refuted, others are developed and tested (Gravemeijer \& van Eerde, 2009). The exploration with new conjectures linked to the HLT, generally, are made by setbacks that occurred in the classroom, such as student strategies that had not been planned or tasks that were too difficult (Bakker \& van Eerde, 2015).

In our research, three cycles were executed in the phase of the teaching experiment (see Figure 2) in a Spanish university with first-year engineering students. Each cycle included an intervention in the classroom of five hours distributed into three sessions where the tasks defined in the HLT were worked on in groups (from 3 to 5 students).

The assumptions about the starting points of the students, in each cycle of the teaching experiment, were that they understood the notion of vectors and had not previously worked with mathematical modeling or the concepts of spanning set or span. This information was provided by the teacher in charge of the course in each of the cycles of the teaching experiment.

The primary source of data was the written protocols of the tasks developed by the students. This was complemented by video and audio recordings of the work of some group, interviews, and individual written evaluations from the students (made after the intervention in the classroom). The above is part of the typical data collection during the phase of the teaching experiment (Bakker \& van Eerde, 2015). The data collected in each cycle of the teaching experiment is shown in Table 2. 
Table 2. The data collected in each cycle of the teaching experiment

\begin{tabular}{ccccc}
\hline $\begin{array}{c}\text { Teaching } \\
\text { experiment cycle }\end{array}$ & $\begin{array}{c}\text { Number of written } \\
\text { protocols }\end{array}$ & $\begin{array}{c}\text { Number of recording in audio } \\
\left(\mathbf{N}^{\circ} \text {. a) or video }\left(\mathbf{N}^{\circ} \text {. v) }\right.\right.\end{array}$ & $\begin{array}{c}\text { Number of individual } \\
\text { evaluations }\end{array}$ & $\begin{array}{c}\text { Number of students } \\
\text { interviewed }\end{array}$ \\
\hline 1 & 8 & $\mathrm{~N}^{\circ}$. a: 1 and $\mathrm{N}^{\circ} . \mathrm{v}: 1$ & 22 & 3 \\
2 & 14 & $\mathrm{~N}^{\circ}$. a: 2 and $\mathrm{N}^{\circ}$. v: 2 & 44 & 3 \\
3 & 2 & $\mathrm{~N}^{\circ}$. a: 1 and $\mathrm{N}^{\circ}$. v: 1 & 7 & 3 \\
\hline
\end{tabular}

\section{Preliminary analysis}

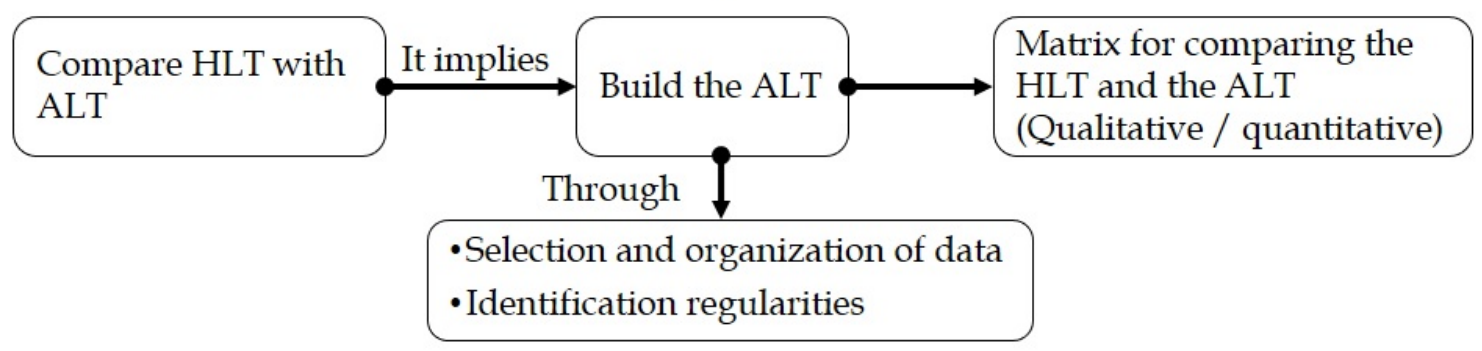

\section{Global analysis}

$\begin{array}{ll}\begin{array}{l}\text { Identify regularities between } \\ \text { cycles }\end{array} & \text { It implies } \\ \begin{array}{l}\text { To evaluate the three ALTs of } \\ \text { each cycle of the teaching } \\ \text { experiment. }\end{array}\end{array}$

Figure 3. Summary of the process performed in the retrospective analysis of our research

\section{Phase 3: Retrospective Analysis}

The retrospective analysis was designed to meet the objective of our study it relates to contributing to the disclosure of a process for making a LIT for concepts of spanning set and span of Linear Algebra.

In phase 3 of IBD based on what is posed by Bakker and van Eerde (2015), the analysis of the interaction between the HLT and the empirical observations of each cycle was the foundation for developing the LIT of our research.

In the IBD, two types of data analysis are necessary (Bakker \& Van Eerde, 2015), the first analysis after each experiment teaching cycle, and, the second analysis of the entire investigation process; that is to say the more general cyclical process. Molina (2006) points out that the first of these, called the preliminary analysis, refers to the analysis of the data after each teaching experiment cycle and leads to decisions regarding future interventions, facilitating both the review and development of the study conjecture. Meanwhile, the global analysis delves into the whole process of experiment and data collected. This leads to the construction of a coherent history of the evolution of the LIT throughout all experimentation process. Thus, according to Gravemeijer and Cobb (2013), we can say that the results of the IBD are empirically grounded. Figure 3 shows a summary of the analysis process carried out in our research.

The preliminary analysis, according to Bakker and van Eerde (2015), consists of comparing the data of the actual learning trajectory (ALT) with the conjectures of the HLT. This is because contrasting the HLT with the observed learning is helpful for the redesign process.

The ALT is the learning process that performs; that is, which the students follow in the context of the implementation of instructional design (Leikin \& Dinur, 2003). The ALT, according to Dierdorp, Bakker, Van Maanen and Eijkelhof (2011), is inferred from the data collected because it is not possible to detect the actual students' learning explicitly.

The ALT of the main tasks of the instructional sequence of each cycle teaching experiment was reconstructed following the steps below:

- Data selection according to the objective of our study and the conjectures of the HLT.

- Organization into tables of students' written answers and of the transcripts of audio and video recordings that were related to these responses. As Molina (2006) indicates, this grouping was beneficial to access the data because during the analysis process it was used at various times, to listen to recordings to determine more precisely how the students did a specific task in the classroom. 
Table 3. Data analysis matrix for comparing the HLT with the ALT

\begin{tabular}{cc|c|c|c}
\hline \multicolumn{3}{c}{ Hypothetical learning trajectory (HLT) } & Actual learning trajectory (ALT) & Match between HLT and ALT \\
\hline Task & $\begin{array}{c}\text { Description of the } \\
\text { task }\end{array}$ & $\begin{array}{c}\text { The conjecture of how } \\
\text { students would respond }\end{array}$ & $\begin{array}{c}\text { Extract of written } \\
\text { or oral response }\end{array} \quad$ Result & $\begin{array}{c}\text { The quantitative impression of } \\
\text { how well the conjecture and } \\
\text { actual learning matched }\end{array}$ \\
\hline
\end{tabular}

- Identification of regularities in each task concerning the types of answers given by the students and the difficulties encountered them.

- Reconstruction of the ALT.

Then, in each cycle of the teaching experiment, we compared the HLT with the ALT through the matrix of qualitative/quantitative data analysis (Table 3) formulated by Bakker Eerde (2015) which is an adaptation of the one formulated by Dierdorp et al. (2011). To this end, data were sought to support or refute the conjectures of the HLT.

Columns 1, 2, and 3 of the matrix (Table 3) summarize the HLT, while columns 4 and 5 synthesize the ALT through of the written responses or extracts from transcripts in conjunction with the description of the results of the investigator.

The last column of the matrix (Table 3) synthesizes how close the conjecture of the HLT was in relation with the ALT through a quantitative approach, which is symbolized by the signs"-", "+" and " \pm ". The sign "-" is used when observations suggest that the conjectures of the of HLT were confirmed by a maximum of one-third of the students. The "+" sign is used in the time that the observations are suggesting that at least two-thirds of students ratified the conjectures of the HLT. Meanwhile, the sign " \pm " is used for intermediate cases, that is to say when more than one-third but less than two-thirds of students confirmed the conjectures of the HLT.

In considering the results of the preliminary analysis, the conjectures of the HLT used in each cycle to start a new cycle of experiments were modified. An example of such an analysis can be seen Cárcamo, Gómez and Fortuny (2016), which disclose the results of the second cycle of the teaching experiment.

In the overall analysis, we observed the three actual learning trajectories (ALTs) of the teaching experiment cycles in order to establish patterns or trends that would allow us to identify: the difficulties faced by students in the process of the building of spanning set and span, the construction that they achieved from these concepts, and the tasks of each HLT that promoted the development of these concepts. Furthermore, this analysis, as mentioned Gravemeijer and Cobb (2013), can allow for the generation of design ideas that go beyond those tested in the classroom.

\section{RESULTS}

The iterative refinement of the first HLT, through of the three teaching experiment cycles, showed us the tasks that give evidence to contribute to the construction of spanning set and span, as well as the construction by which students provide evidence of having mastered these concepts of Linear Algebra. Furthermore, it allowed us to identify the difficulties that the students had during the development of the tasks included in the HLT. All of these elements formed the foundation for the LIT which was developed in this study.

\section{Tasks that Favored the Construction}

In Table 4, we show the main common tasks of three the teaching experiment cycles, in addition to the tasks that were different in each of these cycles. These tasks listed in Cárcamo et al. (2016), Cárcamo, Fortuny and Gómez (2017), Cárcamo, Fortuny and Fuentealba (2018) all showed the results of cycles 1, 2 and 3 of the teaching experiment, respectively. 
Table 4. Summary of the main common and different tasks of the teaching experiment

\begin{tabular}{|c|c|c|}
\hline \multicolumn{3}{|l|}{ Main common tasks } \\
\hline \multicolumn{3}{|c|}{ Task 1: To create a mathematical model that contains vectors and that allows for the creation of secure passwords. } \\
\hline \multicolumn{3}{|c|}{ Task 2: To make an analogy table between their password generator and the concepts of spanning set and span. } \\
\hline \multicolumn{3}{|l|}{ Main different tasks } \\
\hline Cycle 1 & Cycle 2 & Cycle 3 \\
\hline \multirow[t]{2}{*}{$\begin{array}{l}\text { Task } 3 b \text { : To establish whether it is true } \\
\text { or false that the vector }(2,-3) \text { belongs } \\
\text { to the span generated by } C=\{(1,0),(0 \text {, } \\
-1)\} \text {. }\end{array}$} & $\begin{array}{l}\text { Task 3: To determine whether the } \\
\text { sets } A, B \text { and } C \text { generate to } \mathrm{R}^{2} \text {, that is } \\
\text { to say if they are spanning } \\
\text { sets of this space. }\end{array}$ & $\begin{array}{l}\text { Task 3. To conjecture on the value of the range } \\
\text { of a matrix that has the vectors of a set of } R^{2} \text { as } \\
\text { part of its rows, so that said set generates this } \\
\text { span. }\end{array}$ \\
\hline & $\begin{array}{l}\text { Task } 4 a \text {. Given a span of } \mathrm{R}^{2} \\
\text { determine a spanning set for it. }\end{array}$ & $\begin{array}{l}\text { Task 4. To determine if set } C=\{(1,0,0,1),(0,1,0,0)\} \\
\text { is a spanning set of } W=\{(x, y, z, w) / x=w\} \text {. }\end{array}$ \\
\hline
\end{tabular}

$(x, 2 x, x+2 x)$

Figure 4. Written response of task 1 provided by a student who participated in cycle 1 .

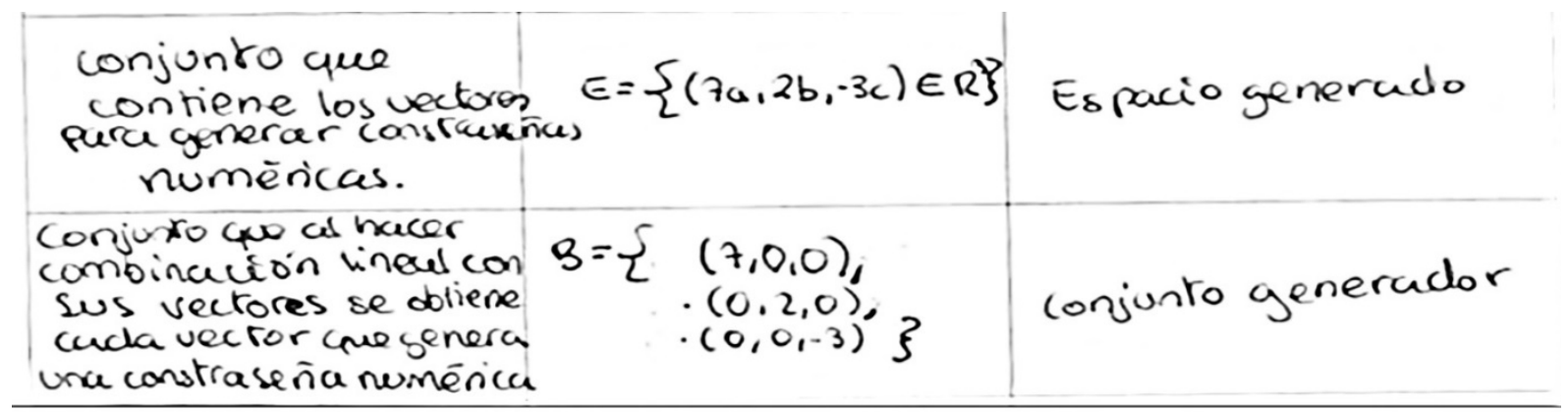

\section{Translation}

Set that contains the vectors to generate numeric passwords

$\begin{aligned} & \text { Set that when building a linear } \\ & \text { combination with its vectors }\end{aligned}=\left\{\begin{array}{l}(7,0,0), \\ (0,2,0), \\ (0,0,-3)\end{array}\right\}$
$\begin{aligned} & (0,0) \text { get each of the vectors that } \\ & \text { generates a numeric password }\end{aligned}$$\quad$ Spanning set
generates a numeric password

Figure 5. Written response of task 2 provided by a student of group 12 who participated in cycle 2 .

In Table 4, we see that the tasks 1 and 2 were presented to students from the 3 cycles of the teaching experiment. The results of these cycles the results match in that the task 1 allowed students to activate their preconceptions of vectors that are necessary for the construction of the concepts of spanning set and span.

In Figure 4, we show the written response of a student of group 4 of cycle 1 where we observed that the student made use of the preconceptions vector because he wrote a vector of $\mathrm{R}^{3}$ as a mathematical model to respond to the task 1.

Concerning task 2, the conclusions of cycle 1 (Cárcamo et al., 2016) and cycle 2 (Cárcamo et al., 2017) indicate that it promoted the students' visualization of the concepts of spanning set and span in a real-world as well as a mathematical context. This gave them the opportunity to distinguish the connection with a real-world situation, as exemplified in a written response of a student from the group 12 of cycle 2 (Figure 5). This response is shown in the second column of two sets, E and B, which are linked to the names of spanning set and span correctly and have an interpretation in the context of passwords.

Meanwhile, the results of cycle 3 (Cárcamo et al., 2018), regarding Task 2, match with previous cycles, but also highlight that it was important for students to continue to deepen their knowledge on spanning set and span since, 


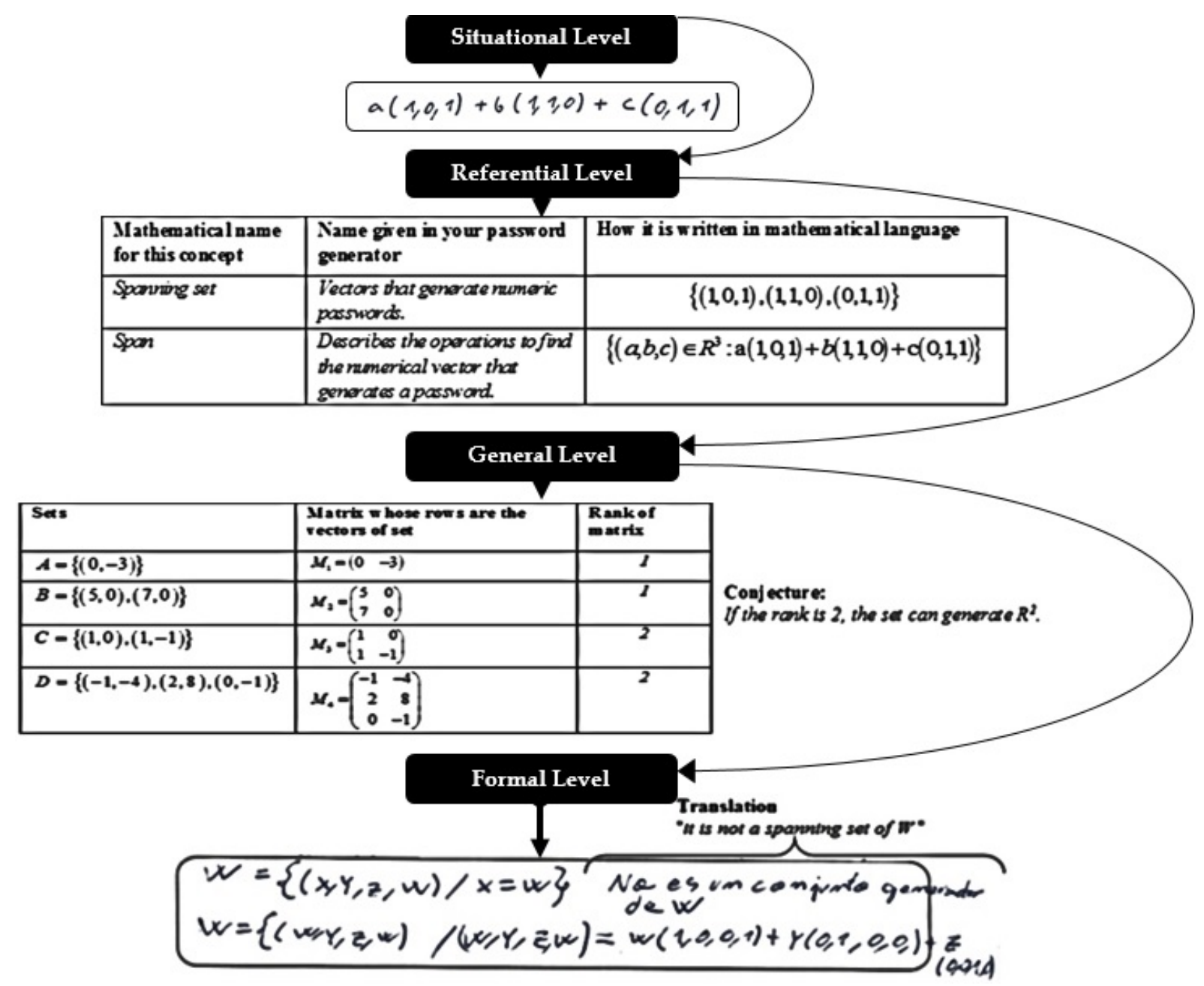

Figure 6. Schema linking the written answers provided by a student from group 1 who participated in cycle 3 with the different activity levels of the emergent models.

with the use of an analogy table, they created an initial example in analytical register of both concepts. The latter is also observed in the second column of Figure 5.

Also, in Table 4, we observed that there were variations in the tasks that came after the first two in each HLT. This is because of the difficulties identified in each cycle of the teaching experiment. In the case of cycle 1, the main difficulties detected were in the application of the concepts of spanning set and span, specifically, the questions relating to determining a span or plotting a spanning set $\mathrm{R}^{2}$. We believe this difficulty emerged because the students had not previously deducted the properties of spanning set and span.

For this reason, we suggest rethinking task 3, because there are questions both of properties and of spanning set and applications of span (Cárcamo et al., 2016). This suggestion was incorporated into the HLT of the second cycle, so task 3 was redesigned and focused on the properties of these concepts of Linear Algebra. Furthermore, we add an individual task 4 on the applications of these concepts (Cárcamo et al., 2017).

In cycle 2, we identified that the analytical representation of spanning set and span was the main difficulty (Cárcamo et al., 2017). To help the students overcome this difficulty, we proposed adding a task in cycle 3 in which the students work in groups on questions about the applications of spanning set and span, and then also individually on these questions. We believe this would help each student understand the analytical notation of these concepts. This suggestion was incorporated into the HLT third cycle.

The results of cycle 3 gave evidence that students passed through the different levels of the activity of emergent models by solving the sequence of HLT tasks (Cárcamo et al., 2018). In Figure 6 a diagram linking the answers written by a student who participated in group 1 of cycle 3 with different levels of activity emergent models it is presented. 
Table 5. Hypothetical process of learning the final tasks of each HLT used in the teaching experiment

The hypothetical learning process of the final tasks of cycle 1

\section{(a) Students coordinate the analytical notation} associated with the spanning set and the span and, they recognize that the set $B$ has the notation of a span while the set $C$ corresponds to the notation of a spanning set. (b) Students coordinate the analytical notation and the cardinality of the spanning set and the span, then they identify that sets $B$ and $C$ do not have the same number of elements, since $B$ represents a span by what has infinite vectors, unlike $C$ which represents a spanning set and which contains only three vectors (Task 3a).

(a) Students are coordinating the definition of spanning set and span, and they identify $C=\{(1,0)$, $(0,-1)\}$ as a spanning set of a space of $R^{2}$. (b) Using the definition of the span, they perform a linear combination with the vectors of the $C$-set and generic scalars and match this linear combination with the vector $(2,-3)$ to determine if these scalars exist. (c) Students using the definition of the span and that the vector $(2,-3)$, they can be written as a linear combination of the vectors of set $C$, they determine that the vector $(2,-3)$ belong to the span generated by $C$ (Task 3b).

\section{The hypothetical learning} process of the final tasks of cycle 2

(a) Students coordinate the mathematical elements

associated with the spanning set

and the span for particular cases of sets in the context of $R^{2}$. Then, they deduce that a set in $R^{2}$ generates a span $R^{2}$ when it has at least two linearly independent vectors (Task 3).

(a) Students coordinate the definitions of spanning set and the span together with their properties; then they determine how to obtain a spanning set given the span it generates. (b) Observing the characteristics of the given subspace of $R^{4}$ and, using the definition of the span, they propose a spanning set for the subspace of $R^{4}$ (Task 4a).

\section{The hypothetical learning process of} the final tasks of cycle 3

\section{(a) Students coordinate the} mathematical elements associated with the spanning set and the span (notation, cardinality, and inclusion) with the concept of a matrix range for particular cases. (b) They extend the observations of these particular cases to a general case, and they infer the property that the span can be generated by different sets and even, with different cardinality (Task 3). Students use the definitions of both, spanning set and span, together with their properties, to determine if a specific set is a spanning set of a given span (Task 4).

\section{Translation}

\section{$\overbrace{\text { Lierfo }}^{\text {It is true }}, 2 \cdot(2,0)+3 \cdot(0,-1)=(2,-3)$}

Figure 7. Written response of task $3 \mathrm{~b}$ provided by the student 1 who participated in cycle 1.

The written answers by the student 1 (Figure 6) gave us indications that these tasks contributed to the construction of spanning set and span. For this reason, we think they should be considered in the LIT of our research.

\section{Construction of Spanning Set and Span}

The hypothetical learning process that led to the design of new tasks, and that was different in each HLT of the teaching experiment (Table 5), allows us to establish that the HLT applied in a subsequent cycle, required a greater cognitive demand of the students on the concepts of spanning set and span.

The conjectures of the task $3 a$ of cycle 1 asked the students to coordinate the mathematical notation of spanning set and span with the cardinality of each one of these to identify specific sets with some of these concepts. Also, task $3 \mathrm{~b}$ of cycle 1 required the students to recognize the spanning set of specific space in its analytical record in order to determine if there was a linear combination with the vectors of said set that would allow for the creation of a given vector. In Figure 7, we presented an example response to the question $3 \mathrm{~b}$ which shows that the student found scalars, 2 and 3, which allow for the creation of a linear combination with the vectors $(1,0)$ and $(0,-1)$ to obtain the vector $(2,-3)$.

Meanwhile, the conjectures of the tasks 3 of cycle 2 asked students to coordinate the mathematical elements related to the spanning set and span, and relate these concepts to deduce the idea that a spanning set of $R^{2}$ if it has at least 2 linearly independent vectors. Also, the task 4 a of cycle 2 required them to use the features of spanning set and span and its properties in other situations, for example, to determine a spanning set of a particular space. This is exemplified in the written response presented in Figure 8. In this written response, we observed that the student replaced conditions for vectors belonging to the set $W$ and proposed a spanning set for $W$ that is suitable. 


\section{Translation}

Given the set $\mathrm{W}=\{(x, y, z, w) / x=z, y=w=0\}$.

(a) Find a spanning set of $\mathrm{W}$

Dado el conjunto $W=\{(x, y, \mathrm{z}, \mathrm{w}) / x=z, y=w=0\}$.

(a) Indica un conjunto generador de $W$.

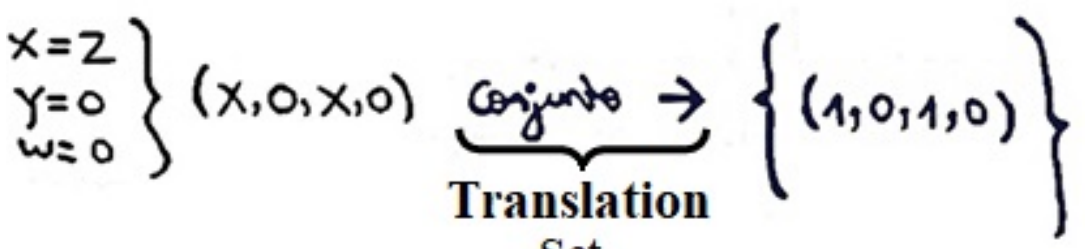

Set

Figure 8. Written response of task 4a provided by the student 3 of group 13 who participated in cycle 2 .

\begin{tabular}{|c|c|c|c|}
\hline \multicolumn{4}{|c|}{ Translation } \\
\hline$\overbrace{\text { Sets belonging to } \mathbb{R}^{2}}$ & $\begin{array}{l}\text { Matrix whose rows are } \\
\text { the vectors of the set }\end{array}$ & Matrix rank & Your conjecture \\
\hline $\begin{array}{l}\text { Conjunto } \\
\text { pertenecientes a } \mathbb{R}^{2}\end{array}$ & $\begin{array}{l}\text { Matriz cuyas filas son los } \\
\text { vectores del conjunto }\end{array}$ & $\begin{array}{l}\text { Rango de } \\
\text { la matriz }\end{array}$ & Su conjetura: \\
\hline$A=\{(0,-3)\}$ & $M_{1}=\left(\begin{array}{ll}0 & -3\end{array}\right)$ & $R_{\pi_{1}}=n$ & $\begin{array}{l}\text { El rango de la matriz } \\
\text { debe ser igual a } 2 \text {. }\end{array}$ \\
\hline$B=\{(5,0),(7,0)\}$ & $M_{2}=\left(\begin{array}{ll}5 & 0 \\
7 & 0\end{array}\right)$ & $\operatorname{lol}_{2}=n$ & $\begin{array}{c}\text { Translation } \\
\text { The matrix rank must be }\end{array}$ \\
\hline$C=\{(1,0),(1,-1)\}$ & $M_{3}=\left(\begin{array}{rr}1 & 0 \\
1 & -1\end{array}\right)$ & $R_{\pi_{3}=2}$ & equal to 2 \\
\hline$D=\{(-1,-4),(2,8),(0,-1)\}$ & $M_{1}=\left(\begin{array}{rr}-1 & -4 \\
2 & 8 \\
0 & -1\end{array}\right)$ & $R_{\mathrm{H}_{4}}=2$ & \\
\hline
\end{tabular}

Figure 9. Written response of task 3 provided by a student of group 2 of HTL of the cycle 3.

Translation

It is not, because it is missing $(0,0,1,0)$

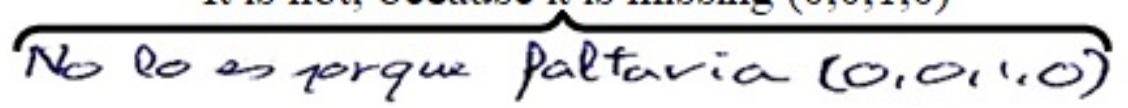

Figure 10. Written response of task 4 provided by a student of group 2 of HTL of the cycle 3

Finally, the conjectures of the task 3 of cycle 3 asked students to coordinate the associated mathematical elements to the spanning set and span (notation, cardinality, and inclusion) along with the concept of matrix rank, from which they deducted the idea the span can be generated, and even different sets of diverse cardinality can be generated as well. This is exemplified in Figure 9. Here we see that a student from group 2 of cycle 3 coordinated the notation of the spanning sets of $\mathrm{R}^{2}$ with the concept of matrix rank, and from this, he wrote as a conjecture that "the matrix rank must be equal to 2 " for a set that contains the vectors of rows of the matrices can generate the space $\mathrm{R}^{2}$.

Also, in a similar manner to cycle 2, in cycle 3 they were required to use the features of spanning set and span and its properties in other situations, including determining whether a certain set was a spanning set of a given space. In particular, they were asked to indicate whether $C=\{(1,0,0,1),(0,1,0,0)\}$ was a spanning set for the space $W$ $=\{(x, y, z, w) / x=w\}$. A student from group 2 correctly answered this question by stating that "it is not, because it is missing $(0,0,1,0) "$ (see Figure 10). 
Table 6. The LIT for the concepts of spanning set and span

\begin{tabular}{|c|c|c|c|}
\hline Objective and task & Hypothetical learning process & Tools & Teacher actions \\
\hline $\begin{array}{l}\text { Objective 1: Identify some } \\
\text { difference between the spanning } \\
\text { set and the span. } \\
\text { Task 1: Create a password } \\
\text { generator based on a linear } \\
\text { combination. Then, determine two } \\
\text { sets linked to the password } \\
\text { generator with specific } \\
\text { characteristics and determine } \\
\text { some difference between these } \\
\text { sets. }\end{array}$ & $\begin{array}{l}\text { (a) Students use their current knowledge of linear } \\
\text { combination to construct a linear combination of } \mathrm{R}^{\mathrm{n}} \\
\text { with generic scalars. (b) They provide at least one } \\
\text { example of a vector that arises from the linear } \\
\text { combination they built. (c) They coordinate their } \\
\text { knowledge about sets and the linear combination to } \\
\text { construct and describe two sets, for example, } S \text { and } \\
V \text {. They describe } S \text { analytically by extension, and } S \\
\text { have the vectors that allow the linear combination to } \\
\text { be made. They describe } V \text { by understanding, and } V \\
\text { contains all the vectors that are generated when } \\
\text { giving values to the scalars of the linear combination. } \\
\text { (d) They characterize the sets } S \text { and } V \text { regarding their } \\
\text { cardinality, mathematical notation and, the inclusion } \\
\text { of one over another. }\end{array}$ & $\begin{array}{l}\text { Vectors, linear } \\
\text { combinations and, } \\
\text { two sets of } R^{n}(A \text { and } \\
B) \text { related to the } \\
\text { mathematical model } \\
\text { that are examples of } \\
\text { spanning set and } \\
\text { span. }\end{array}$ & $\begin{array}{l}\text { *The teacher tries that the } \\
\text { students correctly use the } \\
\text { concepts of vector and linear } \\
\text { combination. } \\
\text { *The teacher encourages } \\
\text { students to use the mathematical } \\
\text { modeling cycle to create a } \\
\text { password generator. } \\
\text { *The teacher verifies that the two } \\
\text { sets of the password generator of } \\
\text { the students correspond to a } \\
\text { spanning set and span. }\end{array}$ \\
\hline $\begin{array}{l}\text { Objective 2: Determine the } \\
\text { characteristics of a spanning set } \\
\text { and a span. } \\
\text { Task 2: Students make an analogy } \\
\text { table between their password } \\
\text { generator and the concepts of } \\
\text { spanning set and span. Then, they } \\
\text { observe the analogy tables of } \\
\text { your classmates to establish } \\
\text { characteristics of spanning set and } \\
\text { span. }\end{array}$ & $\begin{array}{l}\text { (a) Students characterize the spanning set and the } \\
\text { span regarding its cardinality and mathematical } \\
\text { notation. (b) They look for the characteristics of the } \\
\text { spanning set and span in the sets } S \text { and } V \text {. (c) They } \\
\text { link the set } S \text { with the concept of spanning set, and } \\
\text { the set } V \text { relate it with the concept of the span. (d) } \\
\text { They observe the sets and the corresponding analogy } \\
\text { tables of their classmates to describe spanning set } \\
\text { and span regarding the elements that each of these } \\
\text { sets contains. }\end{array}$ & $\begin{array}{l}\text { The sets } A \text { and } B \text { of } \\
\mathrm{R}^{\mathrm{n}} \text { that are examples } \\
\text { of spanning set and } \\
\text { span, respectively. } \\
\text { These sets were } \\
\text { written by their } \\
\text { classmates. }\end{array}$ & $\begin{array}{l}\text { The teacher introduces the } \\
\text { definitions of spanning set and } \\
\text { span relating these definitions to } \\
\text { task } 1 . \text { The teacher guides the } \\
\text { students to characterize these } \\
\text { concepts. }\end{array}$ \\
\hline $\begin{array}{l}\text { Objective 3: Identify some } \\
\text { properties linked to spanning set } \\
\text { and span. } \\
\text { Task 3: Conjecture properties } \\
\text { about spanning set and span. }\end{array}$ & $\begin{array}{l}\text { (a) Students coordinate the mathematical elements } \\
\text { associated with the spanning set and span (notation, } \\
\text { cardinality, and inclusion) with the concept of a } \\
\text { matrix range for particular cases. (b) They extend the } \\
\text { observations of these particular cases to a general } \\
\text { case and infer the property that the span can be } \\
\text { generated by different sets, even with different } \\
\text { cardinality. }\end{array}$ & $\begin{array}{l}\mathrm{R}^{\mathrm{n}} \text { sets different to } \\
\text { the sets worked in } \\
\text { the context of the } \\
\text { passwords. }\end{array}$ & $\begin{array}{l}\text { The teacher formalizes the } \\
\text { properties of spanning set and } \\
\text { span. }\end{array}$ \\
\hline $\begin{array}{l}\text { Objective 4: Apply the concepts of } \\
\text { spanning set and span. } \\
\text { Task 4: Apply the concepts of } \\
\text { spanning set and span. }\end{array}$ & $\begin{array}{l}\text { Students, through their reflection and awareness of } \\
\text { their activity and its effects, use the characteristics of } \\
\text { spanning set and span together with their properties } \\
\text { in other situations, such as determine if a specific set } \\
\text { is a spanning set of a particular span. }\end{array}$ & $\begin{array}{l}\text { Sets of } \mathrm{R}^{\mathrm{n}} \text { different } \\
\text { to the sets worked in } \\
\text { the previous tasks. }\end{array}$ & $\begin{array}{l}\text { The teacher guides the students } \\
\text { in the resolution of the problems. }\end{array}$ \\
\hline
\end{tabular}

According to the results obtained in cycles 1, 2 and 3 of the teaching experiment, it is important to mention that each was evidence that the ALTs of at least some of the students, approached the conjectures of the HLT. In the results of the first cycle (Cárcamo et al., 2016) we observed that most students differentiate between spanning set and span, and also they verified whether a vector is belonging to a specific span (Figure 8). In the second cycle (Cárcamo et al., 2017) we found that many students made conjectures and some properties obtained from the spanning set of a specific space (Figure 9). In the third cycle (Cárcamo et al., 2018) we noticed that the students did the same as those from the previous cycles and could even determine if a set of $\mathrm{R}^{4}$ generated a subset of $\mathrm{R}^{4}$ (Figure 10).

\section{CONCLUSION}

This research is intended to contribute to furthering the awareness of a process for making a LIT for the concepts of spanning set and span, based on the heuristics of emergent models and mathematical modeling. This proposal is critical for fostering curricular innovations in Linear Algebra. This LIT, as Larsen (2013) points out, describes a trajectory in which students can navigate the distances between a concrete example and the concepts of spanning set and span.

The LIT that we presented in Table 6 comprises the components identified by Gravemeijer (2004a): the objectives for learning, the hypothetical learning process, the tasks, and the tools that will be used. Also, we incorporated the central actions of the teacher during the learning process of spanning set and span because we consider that it is an essential component in the educational planning.

When presenting the LIT, we emphasize that it can serve as a tool to help the teacher regarding guiding the reasoning of his or her students towards the construction of certain mathematical concepts. At the same time, as 
pointed out by Nickerson and Whitacre (2010), the teacher must be aware of and be open to other models of reasoning that can be as valid as those proposed in the LIT.

A LIT, without doubt, can serve as a frame of reference for teachers to build their own learning trajectories for their students. However, we want to emphasize and reiterate what Beer, Gravemeijer and van Eijck (2017) point out in that our proposed LIT "is not intended as a ready-made product, but as a potential viable theory for other researchers, educational designers, and maybe teachers to develop a learning trajectory" (p. 463) on span and spanning set adapted to their situation.

The LIT presented in this research takes as its starting point in the context of creating password vectors. This required students to make use of their previous conceptions of vectors. Then, they were given an initial familiarization of spanning set and span through an analogy table where they wrote two sets referring to the context of the passwords, but which were examples of spanning set and span (See Figure 6). For the students, these two sets were models-of (Gravemeijer, 1999) the work done in the context of passwords and vectors.

Perhaps the most critical change in the students' activity occurred when they made the transition to link spanning set and span in the context of passwords to more general activity (Gravemeijer, 1999), as is the case for the conjecturing of the properties of these concepts (Figure 9). Then, students progressed to a level of more formal activity (Gravemeijer, 1999) when applying spanning set and span to routine tasks, which involved, for example, their determining a spanning set (Figure 8) or determine if a set generated a specific space (Figure 10).

Our research suggests that this LIT based on emergent models and mathematical modeling contributes to the construction of spanning set and span. The use of mathematical modeling helped students to make use of their previous concepts of vectors (Figure 4), and then to link the concepts of spanning set and span in a real-world context, as was the case for the passwords (Figure 5). These two tasks linked to a real context, we believe, help students to avoid feeling confused or disoriented when they start studying these concepts of Linear Algebra (Carlson, 2004) and to avoid being confused (Nardi, 1997).

Moreover, the emergent models (Gravemeijer, 2004b) guided the students to advancing from their previous conceptions to the formal reasoning of the spanning set and span. In Task 1, students were only required to use their previous conceptions of vectors (Figure 4). In Task 2, they identified characteristics of spanning set and span to relate to the context of passwords (Figure 5). In Task 3, students made conjectures about the concepts they were building, and as a result of this, they related them with other definitions, such as matrix rank (Figure 9). Finally, in task 4, the students solved problems that were not algorithmic, where they gave evidence of their understanding of spanning set and span (Figure 10).

We agree with Larsen (2013) that the central purpose of LIT should be to support the design of an instruction sequence for a given context. We hope this LIT will serve as a model for the building of the spanning set and span and to develop local instruction theories of other content in other classroom settings. Also, we hope that this LIT allows changes to the way these concepts of Linear Algebra and other contents of this course are taught. This is because this LIT is based on emergent models and mathematical modeling, which allows the teaching of Linear Algebra from a situation that is real to the student, and not in an abstract manner.

On the other hand, we consider that a limitation of our LIT proposal is the time that should be allocated to be applied in the classroom (about five hours) because we know that, in many cases, the teacher does not spend more than two hours teaching these concepts of Linear Algebra. However, we believe that the teacher should reflect on how valuable it is for students who not only learn the concepts of span and spanning set but also, they can develop skills related to mathematical modeling that are important, so Lesh and Caylos point out (2007), so that these students have a productive participation in the dynamic society in which they find themselves.

\section{REFERENCES}

Bakker, A., \& Van Eerde, H. A. A. (2015). An introduction to design based research with an example from statistics education. In A. Bikner-Ahsbahs, C. Knipping, \& N. Presmeg (Eds.), Doing qualitative research: Methodology and methods in mathematics education (pp. 429-466). New York, USA: Springer. https:/ / doi.org/10.1007/97894-017-9181-6_16

Ball, G., Stephenson, B., Smith, G., Wood, L., Coupland, M., \& Crawford, K. (1998). Creating a diversity of mathematical experiences for tertiary students. International Journal of Mathematical Education in Science and Technology, 29(6), 827-841. https:/ / doi.org/10.1080/0020739980290605

Blum W., \& Leiss D. (2007). How do students and teachers deal with modelling problems? In C. Haines, P. Galbraith, W. Blum, \& S. Khan (Eds.), Mathematical modelling (ICTMA12): Education, Engineering and Economics (pp. 222-231). Chichester, UK: Horwood Publishing. https:/ / doi.org/10.1533/9780857099419.5.221 
Cárcamo, A., Fortuny J., \& Gómez, J. (2017). Mathematical modelling and the learning trajectory: tools to support the teaching of linear algebra. International Journal of Mathematical Education in Science and Technology, 48(3),338-352. https:/ / doi.org/10.1080/0020739X.2016.1241436

Cárcamo, A., Fortuny, J., \& Fuentealba, C. (2018). The emergent models in linear algebra: an example with spanning set and span. Teaching Mathematics and its Applications: An International Journal of the IMA, 37(4), 202-217. https://doi.org/10.1093/teamat/hrx015

Cárcamo, A., Gómez, J., \& Fortuny, J. (2016). Mathematical Modelling in Engineering: A Proposal to Introduce Linear Algebra Concepts. Journal of Technology and Science Education, 6(1), 62-70. https:/ / doi.org/10.3926/jotse.177

Carlson, D. (1997). Teaching linear algebra: Must the fog always roll in? In D. Carlson, C. R. Johnson, D. C. Lay, A. D. Porter, A. Watkins \& W. Watkins (Eds.), Resources for Teaching Linear Algebra, MAA Notes (Vol. 42, pp. 3951). Washington, USA: Mathematical Association of America. https:/ / doi.org/10.1080/03081089708818529

Carlson, D. (2004). The Teaching and Learning of Tertiary Algebra. In K. Stacey, H. Chick, M. Kendal, B. Barton, \& J. C. e Silva (Eds.), The Future of the Teaching and Learning of Algebra, the 12th ICMI Study (Vol. 8, pp. 293-309). Dordrecht, Netherlands: Kluwer Academic Publishers.

Cobb, P., \& Gravemeijer, K. (2008). Experimenting to support and understand learning processes. In A.E Kelly, R.A. Lesh, \& J.Y. Baek (Eds.). Handbook of design research methods in education: Innovations in science, technology, engineering, and mathematics learning and teaching (pp. 68-95). Mahwah, USA: Lawrence Erlbaum Associates.

de Beer, H., Gravemeijer, K., \& van Eijck, M. (2017). A proposed local instruction theory for teaching instantaneous speed in grade five. The Mathematics Enthusiast, 14(1), 435-468.

Dierdorp, A., Bakker, A., Eijkelhof, H., \& van Maanen, J. (2011). Authentic practices as contexts for learning to draw inferences beyond correlated data. Mathematical Thinking and Learning, 13(1-2), 132-151. https:/ / doi.org/10.1080/10986065.2011.538294

Doorman, M., \& Gravemeijer, K. (2009). Emergent modeling: discrete graphs to support the understanding of change and velocity. ZDM Mathematics Education, 41(1-2), 199-211. https://doi.org/10.1007/s11858-008$0130-z$

Dorier, J. L., \& Sierpinska, A. (2001). Research into the teaching and learning of linear algebra. In D. Holton (Ed.), The teaching and learning of mathematics at university level: An ICMI study (pp. 255-274). Dordrecht, Netherlands: Kluwer Academic Publishers. https:/ / doi.org/10.1007/0-306-47231-7_24

Drijvers, P. (2003). Learning algebra in a computer algebra environment: Design research on the understanding of the concept of parameter (Doctoral dissertation). Utrecht University, Netherlands.

Galbraith, P. (2007). Authenticity and goals - Overview. In W. Blum, P. L. Galbraith, H.-W. Henn, \& M. Niss (Eds.), Modelling and applications in mathematics education: The 14th ICMI study (pp. 181-184). New York, USA: Springer. https:/ / doi.org/10.1007/978-0-387-29822-1_17

Gravemeijer, K. (1994). Developing Realistic Mathematics Education: Ontwikkelen Van Realistisch Reken/wiskundeonderwijs. CD-[beta] Press.

Gravemeijer, K. (1998). Developmental research as a research method. In J. Kilpatrick \&A. Sierpinska (Eds.), Mathematics education as a research domain: A search for identity: An ICMI study (Vol. 2, pp. 277-295). Dordrecht, Netherlands: Kluwer Academic. https:/ / doi.org/10.1007/978-94-011-5196-2_3

Gravemeijer, K. (1999). How emergent models may foster the constitution of formal mathematics. Mathematical Thinking and Learning, 1(2), 155-177. https:/ / doi.org/10.1207/s15327833mt10102_4

Gravemeijer, K. (2002, july). Emergent modeling as the basis for an instructional sequence on data analysis. Paper presented at the 6th International Conference on Teaching Statistics (ICOTS-6), Cape Town, South Africa.

Gravemeijer, K. (2004a). Local instruction theories as means of support for teachers in reform mathematics education. Mathematical thinking and learning, 6(2), 105-128. https:/ / doi.org/10.1207/s15327833mt10602_3

Gravemeijer, K. (2004a, July). Creating opportunities for students to reinvent mathematics. Paper presented at the 10th International Congress on Mathematical Education (ICME), Copenhagen, Denmark.

Gravemeijer, K. (2007, December). Emergent modeling and iterative processes of design and improvement in mathematics education. Paper presented at Tsukuba International Conference III (APEC), Tokyo Kanazawa \& Kyoto, Japan.

Gravemeijer, K., \& Cobb, P. (2013). Design research from the learning design perspective. In Plomp T., \& N. Nieveen (Eds.), Educational Design research. Part A: An introduction (pp. 72-113). Enschede: Netherlands: SLO. 
Gravemeijer, K., \& Stephan, M. (2011). Emergent models as an instructional design heuristic. In K. Gravemeijer, R. Lehrer, B. van Oers, \& L. Verschaffel (Eds.), Symbolizing modeling and tool use in mathematics education (pp. 145-169). Dordrecht: Kluwer Academic Publishers. https:/ /doi.org/10.1007/978-94-017-3194-2_10

Gravemeijer, K., \& van Eerde, D. (2009). Design research as a means for building a knowledge base for teachers and teaching in mathematics education. The Elementary School Journal, 109(5), 510-524. https:// doi.org/10.1086/596999

Gravemeijer, K., Cobb, P., Bowers, J., \& Whitenack, J. (2000). Symbolizing, modeling and instructional design. In P. Cobb, E. Yackel, \& K. McLain (Eds.), Symbolizing and communicating in mathematics classrooms (pp. 225-273). Mahwah, USA: Lawrence Erlbaum Associates.

Grossman, S. (1996). Álgebra Lineal [Linear Algebra]. México: Mc Graw Hill (5a Edición).

Julie, C., \& Mudaly, V. (2007). Mathematical modelling of social issues in school mathematics in South Africa. In W. Blum, P. L. Galbraith, H.-W. Henn, \& M. Niss (Eds.), Modelling and applications in mathematics education: the 14th ICMI study (pp. 503-510). New York, USA: Springer. https:/ / doi.org/10.1007/978-0-387-29822-1_58

Kaiser, G., \& Schwarz, B. (2010). Authentic modelling problems in mathematics education-examples and experiences. Journal für Mathematik-Didaktik, 31(1), 51-76. https:/ / doi.org/10.1007/s13138-010-0001-3

Kú (2012). Análisis sobre la comprensión de los conceptos Conjunto Generador y Espacio Generado desde la mirada de la teoría $A P O E$ [Analysis on the understanding of the concepts spanning set and span from the perspective of the APOS theory]. (Doctoral dissertation). Centro de Investigación y Estudios Avanzados del Instituto Politécnico Nacional, Mexico.

Kú, D., Trigueros, M., \& Oktaç, A. (2008). Comprensión del concepto de base de un espacio vectorial desde el punto de vista de la teoría APOE [Understanding the basis concept of a vector space from the point of view of the APOS theory]. Revista Educación Matemática, 20(2), 65-89.

Larsen, S. P. (2013). A local instructional theory for the guided reinvention of the group and isomorphism concepts. The Journal of Mathematical Behavior, 32(4), 712-725. https:/ / doi.org/10.1016/j.jmathb.2013.04.006

Lay, D. (2007). Álgebra lineal y sus aplicaciones [Linear algebra and its applications]. México: Pearson ( $3^{\mathrm{a}}$ edición).

Leikin, R., \& Dinur, S. (2003, February). Patterns of flexibility: Teachers' behavior in mathematical discussion. Paper presented at Third Conference of the European Society for Research in Mathematics Education, Bellaria, Italy.

Lesh, R., \& Caylor, B. (2007). Introduction to the special issue: Modeling as application versus modeling as a way to create mathematics. International Journal of computers for mathematical Learning, 12(3), 173-194. https:/ / doi.org/10.1007/s10758-007-9121-3

Lesh, R., \& English, L. D. (2005). Trends in the evolution of models y modeling perspectives on mathematical learning and problem solving. ZDM Mathematics Education, 37(6), 487-489. https://doi.org/10.1007/BF02655857

Lewis, J. M., \& Blunk, M. L. (2012). Reading between the lines: Teaching linear algebra. Journal of Curriculum Studies, 44(4), 515-536. https:/ / doi.org/10.1080/00220272.2012.716975

Lipschutz, S. (1992). Álgebra Lineal [Linear Algebra]. Spain: McGraw Hill (2nd Ed.).

Molina, M. (2006). Desarrollo de pensamiento relacional y comprensión del signo igual por alumnos de tercero de educación primaria [Development of relational thinking and understanding of the equal sign by third-year primary school students] (Doctoral dissertation). Universidad de Granada, Spain.

Nardi, E. (1997). El encuentro del matemático principiante con la abstracción matemática: Una imagen conceptual de los conjuntos generadores en el análisis vectorial [The encounter of the beginner mathematician with the mathematical abstraction: A conceptual image of the spanning sets in the vector analysis]. Educación Matemática, 9(1), 47-60.

Nickerson, S. D., \& Whitacre, I. (2010). A local instruction theory for the development of number sense. Mathematical Thinking and Learning, 12(3), 227-252. https:/ / doi.org/10.1080/10986061003689618

Niss, M. (2012). Models and modelling in mathematics education. Newsletter of the European Mathematical Society, $86,49-52$.

Plomp, T. (2013). Educational design research: An introduction. In T. Plomp, \& N. Nieveen (Eds.), Educational design research - Part A: An introduction (pp. 10-51). Enschede, Netherlands: SLO.

Simon, M. A. (1995). Reconstructing mathematics pedagogy from a constructivist perspective. Journal for Research in Mathematics Education, 26(2), 114-145. https:/ / doi.org/10.2307/749205 
Stewart, S., \& Thomas, M. O. (2010). Student learning of basis, span and linear independence in linear algebra. International Journal of Mathematical Education in Science and Technology, 41(2), 173-188. https:/ / doi.org/10.1080/00207390903399620

Wawro, M., Rasmussen, C., Zandieh, M., Sweeney, G. F., \& Larson, C. (2012). An inquiry-oriented approach to span and linear independence: The case of the magic carpet ride sequence. PRIMUS, 22(8), 577-599. https:/ / doi.org/10.1080/10511970.2012.667516

\section{http://www.ejmste.com}

